\title{
The Research on the Teaching Effectiveness of the New Media Sports Teaching Mode
}

\author{
$\mathrm{Li} \mathrm{Li}$ \\ Shaanxi Xueqian Normal University \\ Xian, China \\ E-mail: 531942551@qq.com
}

\begin{abstract}
Compared to TV, Radio and Newspaper, the New Media was wildly applied on the field of business and Entertainment which was built on the base of the Digital technology, network technology, mobile technology. The New Media had a significant effect on the teaching environment, teaching content and the learning methods of the Universities. It was a big challenge for the University and Colleague to find a good way to take advantage of the New Media on the sports teaching mode and improve its good effectiveness. This thesis used the research methods of literature review and comparative analysis to give us a clear picture that how the New Media impacted the sports teaching in the university. The author concluded that if we want to improve the teaching effectiveness of the New Media Sports Teaching, we have to optimize teaching links and resources and respect the dominant position of students in the teaching process. Thus, making the full implementation of the reform on the sports teaching goal, promoting the development of sports teaching in the future.
\end{abstract}

Keyword-teaching effectiveness; New Media; sports teaching mode

\section{INTRODUCTION}

The new media culture is coming to its best times with the development of the smart mobile phone, the computer and the digital television. Compared to the traditional ways, the communication process of the new media has the character of multi-direction, interactive, open and personalized. The traditional teaching methods and teaching contents can not meet the needs of the colleague students who take the mobile phone, micro blog and the Wechat as the main learning channel. It was a big challenge for the University and Colleague to find a good way to take advantage of the New Media on the sports teaching mode and improve its good effectiveness. Thus, it is very necessary to apply the new media into the colleague sports teaching, because the new media will enrich the ways of the colleague sports teaching and motivate the learning motivation of the students at utmost.

\section{The AdVAntages OF THE New Media}

The new media is based on the development of the internet, satellites, wireless communication network, computer and the mobile phone, which makes its mode of propagation do not limited by the time and space. So the new media is quickly welcomed by great number of the young people because of it is much convenient to the learning, working and living. The colleague students who live in the era of the internet as the main theme, can accept the new media much more easier. Obviously, the colleague students like using micro blog, Wechat, E-book and social networks and take them as the most popular things.

The character of multi-direction, interaction, open and personalization of the new media promote its own prosperity and development. Such as using the social network, people can leave their message on the internet at any time no matter where they are, the Wechat group and QQ group can provide a platform for lot of people to communicate at the same time; the micro blog can let people knew want they are interested in. In a sentence, the new media meet the needs of people to fashion, information and real time interaction. The rich and renewable information of the social network make people almost know everything happens on the world. Thus, every government including China support the development of the new media.

\section{THE IMPACT OF THE NEW MEDIA TO COLLEAGUE SPORTS TEACHING}

\section{A. The New Media Teaching Mode Optimizing the Allocation of the Resources, It Is More Interactive and Improving the Sports Teaching Effectiveness}

The traditional colleague sports teaching always take the teacher as the subject, neglect the feelings of the students. Because that the colleague students are coming from different places and having different sports abilities, the traditional teaching methods (teaching the sports theory first, then the action second) can not arose the interest of the students. At last, the situation that most students like sports but do not like spots class happens, it is in the certain extent waste the teaching resources.

It is easier for the students to learn and understand the teaching contents, if the colleague sports teaching applied the PPT to show the sports theory and sports action. Because of the mobile phone is more fast and easy to carry, it becomes the necessary things of the colleague students. With the help of the mobile phone, the students can set up Wechat group, QQ group, which can be used to transform the teaching 
contents before class. So that the students can get a general view of what they are going to learn, take the questions to the class for the teacher to answer. With the assistant teaching tools of the new media, it can greatly improve the teaching effectiveness. After the traditional teaching, the students can make a discussion of what they learned with the help of the new media (Wechat group, QQ group), the teacher can the questions of the students at any time. The other good point is that the new media can help those who are too shy to talk in the traditional class and arise their learning interest, improve their learning effectiveness.

The new media sports teaching are unrestricted by the weather or the physic distance, it can be used indoors or outdoors, in the dormitory or the library, as long as the internet is available. Meanwhile, the students can learn the sports contents without the restriction of time and space. The new media teaching mode is gradually changing the teaching and learning ways of the people, it is optimizing the allocation of the resources, more interactive. Because the teaching resources are no longer limited to the teachers and the books, the learning time are much more free, not only in the class.

\section{B. The Students' Subjectivity Becomes Stronger and the Teaching Environment Is Optimizing}

The teaching environment including the teaching places, teaching facilities, school and class spirit and interpersonal relationship. So the new media teaching mode can do a lot and greatly improve the class size and the interpersonal relationship. This change makes the Students' subjectivity much more stronger. In the process of applying the new media teaching mode, the relationship between the teacher and the students in the educational communication has been changed. If we use the new media technology in two-way communication more flexible, we can achieve the aim of the information feedback in the forms of one-to-one or one-tomany way. It is greatly broadening the channels of information dissemination, and making the sports teaching from one center change to the multi center direction.

The research focuses of colleague sports are meeting the needs of the students and improving their physical quality and sports ideas, because the students are the subject of the sports teaching. Applying the new media sports teaching mode, the teacher can let the students to make a preview of the learning material. Even more the students can make a report teaching like the teacher. By doing so, it can greatly arise the students' interest and motivate their learning motivation.

Another advantage of the new media is that, it is good to cultivate students' innovative spirit and practical ability. The cultivation of innovative ability is the soul of quality education. When the teacher applied the new media as their assistant teaching tools, they must pay attention to cultivate the students' innovation. The design of the course can not just focus on the knowledge objectives, it must make the students face the situation of knowledge and problem, inspiring students to explore, and cultivating their innovative ability during the problem solving process. Practice is the core of sports education. The students can feel the fun of the sports once they transform the sports theory into their own ability with the guiding of their teacher. Thus, it lays the foundation for Lifelong Physical Education.

\section{The New Media Can Promote the Fair Competition of the Sports, Enhance Students' PE Quality}

At one side, the new media give students lots of convenient and changes the way they live, at another sides, most of students become lazy because of the new media, it has a big negative effect on the students PE quality. The bad effects of the new media often through the network novels, network games and lot of APP on the mobile phone to effect the students. At last, lots of the students neglect the sports and pay much attention on the games. So, how to use the good effects of the new media to improve the students' PE quality becomes the top priority foe the colleagues. The author finds that if we want to improve the students' PE quality, the colleague must do the following things: First of all, the colleague should try every means to arise the interest of the students to the sports, and encourage them to insist on ding the sports; Secondly, the colleague should teach and improve the sports skills of the students, so that the students will become much confident; Thirdly, the colleague should help the students organize lots of sports games and provides all kinds of facilities, so that the students will take sports as the life long hobby. The author believes that after doing these kinds of things, the colleague students' PE quality will improve quickly.

The basic responsibility of the colleague teacher is that teaching students the basic knowledge and the basic skills in order to let students develop good psychological quality. But, we all believe that the competitive sport is the best way to select the sports talents and the best way to improve the level of the sports teaching. After the sports competition, the students not only can improve their skill level and physical quality, but also cultivate their spirit of loving sport and competing.

The fairness of the new media is also reflected in the following aspects: because of the size of the class, the position of the students, the weather and the light, some of the students always can not see clearly while the teacher doing the action in the traditional class. The new media teaching mode solve this problem, the teacher can make a video of the class and play it again and again, the students can also make a review at home. This method not only relieve the teachers' working, but also form the habit of selflearning ability of the students, making a good foundation for their future development.

With the development of the new media, it not only improves the effectiveness of the sports match, but also improves the accuracy of the match. It motivates the students' passion to part in the competition and means a lot to the cultivation of the players' skills and PE quality. For example, in the match of jumping, the judge can use the displacement transducer to mark the players' score, and make a recording of the match with the help of the video camera. So after the match, the player can know their score clearly 
without any question. It enhances the fairness of the game in a great extent. Also in the long distance running match, most of the players will have the phenomenon of hypoxia during the running. With the help of the megaphone, they can play some music to relax the player. Or through the living video of the running match, it can be used to encourage the player to insist on finishing the game. In one sentence, with the help of these new media tools, the students and players can gain a lot, and their level of sports competition can also improve in a great extent.

\section{The InNOVATION OF THE New Media SPORTS Colleague TeAching}

\section{A. The Innovation of the Multimedia Teaching}

Nowadays, most of the colleagues and universities pay lots of attention to application of the new media to the teaching process. The sports teaching as the necessary part of the colleague teaching, it plays a important role for the cultivation of the students' healthy body and spirit. So it will become a big motivation for the innovation of the sports teaching, if the colleague applies the new media into the sports teaching process. We all know that the multimedia teaching has been widely applied in the teaching process, such as computer, projector, PPT, video and audio, which can make the students much more easier to understand the class contents. Under this situation, the author believes that the multimedia teaching should not only limited to the PPT and the projector, but also includes the digital TV. While during the process of the colleague sports teaching, the teacher can first introduce the background of the class with the help of the video, arise the interest of the students, then the teacher make a demonstration of the sports actions and ask the students to follow. By doing this, the students can take questions to study, and they can learn much faster and easier.

\section{B. The Innovation of the Interactive Teaching Mode}

The new media has the character of the interactive, through the new media platform, the teacher to the students, the students to the students, can interact with each other conveniently. Among the communicative software, such as QQ, Wechat, they can all be used to interact by the teachers and the students, which push forward the development of the sports teaching.

While in the process of the sports teaching, the teacher and the students can build the QQ group, they can make a evaluation of the sports teaching contents; the teacher can also answer the questions of the students, or upload the relevant material to the QQ. During the interactive process, the teacher can find their teaching problems and the students' problems, then the teacher can make a revise of their teaching and add more interest thing which the students care. By doing so, the teaching effectiveness can make a big progress. Meanwhile, with the development of the technology and the economic, people' s attitudes to the new media also change. The interactive character of the new media can promote the communication of the people and make the colleague sports teaching more welcomed by the students and meet their needs.

\section{The Innovation of the Collaborative Teaching Mode}

With the development of the Internet, the information change between people becomes much more easier. Such as the searching tools as BAIDU, GOOGLE and SOUGOU, they have become the most effective ways for the people to search the information. According to the statistics, more than 90 percent of the students are likely to use BAIDU to solve their problem or find their answer. So if the colleague sports teaching take good advantage of the new media's shareness and interactivity, then the colleague students can find a more easier way to gain their knowledge. At the same time, the colleague will find much pleasure of searching the knowledge and improve their computer skills. The sports teacher can also use the new media teaching mode to make their class more interesting. Because of the good audio and visual effects of the new media sports teaching, more and more students begin to like it and the teaching effectiveness also improves a lot. Therefore, the colleague teacher should take good use of the new media teaching mode, and improve their teaching theory and teaching mode.

\section{How to TAKE USE OF THE NEW MEdA'S ADVANTAGES AND AVOID ITS DISADVANTAGES}

We can find that the new media sports teaching mode makes some changes for the colleagues sports teaching, while there are still some limits for it: First of all, because of the development of the technology, both the teacher and the students can gain the access to the information. In other words, the role of the teacher will decline day by day, it is a big challenge for the teacher to maintain their authority. Secondly, only the teacher improve the self ability and skill can they used to the development of the new media, it will bring a intense felling for the teacher if they are under this situation for a long time. Lastly, the new media system has certain limitations, it dose not have a clear regulation for the information and also lack the emotional interaction.

So, during the reform process of the colleague education, we should take use of the new media's advantages and avoid its disadvantage. At the same time we should maintain the emotional interaction of the traditional class. At one side, the new media sports teaching mode is good to the formation of the students' cognitive structure and sports ability. At another side, the new media sports teaching mode is good to form the students' habitation of the doing exercise and living in a healthy way. It can help students to use what they have learned into their daily life and cultivate their spirit of collectivism.

All in all, the advantages of the new media sports teaching mode can be summarized as follows: Firstly, the new media sports teaching mode gives a clear visual image, it overcomes the disadvantage of abstract in the traditional teaching; Secondly, the dynamic simulation process of the new media sports teaching mode let the students know clearly the important and hard points of the class; Thirdly, the new media sports teaching mode is more interactive and 
easier for students to take part in; Fourth, the new media sports teaching mode breakthrough visual limitations, it let students to know the core of the class; Fifth, the new media sports teaching mode can be repeated over and over again, so that if the students forget the learning content, they can learn it again with the help of it; Last but not least, the new media sports teaching mode can save a lot time and space, it can improve the effectiveness of the teaching. Until now, the new media sports teaching is welcomed by most of the colleague students, because it gives a good exhibition of the learning material with the combination of the video and picture. Therefore, if the sports teacher wants to improve the teaching effectiveness optimizing their teaching mode, they should take good use of the new media and apply it into their teaching class in the future.

\section{REFERENCES}

[1] Yelena Karavayeva. The Understanding of Physical Education_[A]. "17th international scientific congress: olympic competitive sport and sport for all" Conference Proceedings [C]. 2013

[2] The analysis of the PE curriculum.[A]. Proceedings of 2008 International Convention on Science, Education and Medicine in Sport (Volume I) [C]. 2008

[3] Suherman,. Teachers' implication on the development of curriculum and teaching models in physical education [A]. Proceedings of 2008 International Convention on Science, Education and Medicine in Sport (Volume I ) [C]. 2008

[4] Jia-jun XIANG, Zhi-jin HE. The Train of Thought and Method of Working on the Curriculum Framework of the PE Major [A]. Proceedings of the Xi'an 2012 International Conference of Sport Science \& Physical Education Volume II : Physical Education and Innovation[C]. 2012

[5] Linghe KONG, Anna SUN. A Comparison and Analysis on Curriculum Setup of Physical Education in Higher Institutions of China [A]. Proceedings of the Xi' an 2012 International Conference of Sport Science \& Physical Education Volume I : Science and Innovation in Sport[C]. 2012

[6] Ying hao LU, Wei zhong WANG. Improving the Teaching Quality of Physical Education in University by Course construction [A]. Proceedings of the Xi'an 2012 International Conference of Sport Science \& Physical Education Volume III: Physical Education and Health[C]. 2012

[7] Ennis, C. Reproducibility of effect from a curriculum intervention study in physical education [A]. Proceedings of 2008 International Convention on Science, Education and Medicine in Sport (Volume I ) $[\mathrm{C}] .2008$

[8] Analysis of the Current Teaching Situation and Countermeasures of Yoga Course in Anyang Institute of Technology [A]. Proceedings of 2010 International Conference on Sport Medicine, Sport Science, and Computer Science (SMSSCS 2010) [C]. 2010

[9] A comparison of college physical education curriculum between China and foreign countries [A]. Proceedings of 2008 International Convention on Science,Education and Medicine in Sport (Volume I ) $[C] .2008$

[10] Kang Fan. Planning and Measures of Public Curriculum of Physical Education in University $[\mathrm{A}]$. "17th international scientific congress: olympic competitive sport and sport for all" Conference Proceedings [C]. 2013

[11] Li Lin. Effective classroom teaching physical education evaluation. China Education Innovation Herald . 2011

[12] Ji Yuanbo.Expo physical education class teaching efficiency. Sports on the background of new curriculum . 2011

[13] Zhang Lining. Pay attention to sports teaching and build "effective teaching". Modern Reading (EDUCATION EDITION) . 2011
[14] Liu Junxia, Chen Yuxia. New Curriculum Effective Teaching . 2011

[15] Chen Kun.How to carry out efficient sports teaching. The Friends of Students (junior middle school) . 2011

[16] Shang Wenjin.Constructing effective classroom teaching of middle school sports. Sport . 2011

[17] Shannon C E,Weaver W.The Mathematical Theory of Communication. 1949

[18] Huang Xiaochuan. New media landscape of public relations. PR Magazine . 2009

[19] Kuang Wenbo.New media is the mainstream media. 2011

[20] Wu Yinsheng, Mei Jianbing.Some inspiration for the rapid development and psychological warfare in the use of social media. National Defense Science and Technology . 2011

[21] Li Ting. Network technology assisted applications on professional teaching. Journal of Wuxi education institute .2006

[22] W. Howard Levie, Richard Lentz. Effects of text illustrations: A review of research [J]. Educational Communication \& Technology . 1982 (4)

[23] Darla M Castelli, Leah Fiorentino. Physical Education Technology Playbook. 2008

[24] Dale,E. Audiovisual Methods in Teaching . 1969

[25] AECT.The Field of Educational Technology:A Statement of Definition. Audio-Visual Instruction . 1972

[26] Sugiyono. 《Metode Penelitian Pendidikan(pendekatan kuantitatif, kualitatif dan R\&D). 2010

[27] Yusuf,M.O.Information and communication technology and education: Analysing the Nigerian national policy for information technology. International Education Journal . 2005

[28] Ananta Tri Prasetya.Making Of Volleyball Technique Learning As Interactive Multimedia Using Adobe Flash Media. . 2012

[29] Arikunto,Suharsimi.Prosedur Penelitian: A Practice Approach. Edisi Revisi VI. . 2006 